\title{
NANOLEAKAGE PHENOMENON ON DEPROTEINIZED HUMAN DENTIN
}

\author{
Patrícia de Britto Pereira Garcia DUARTE ${ }^{1}$, Eduardo Moreira da SILVA²
}

1- DDS, MSc, Department of Restorative Dentistry, School of Dentistry, Federal Fluminense University, Niterói, RJ, Brazil.

2- DDS, MSC, PhD, Assistant Professor, Department of Restorative Dentistry, School of Dentistry, Federal Fluminense University, Niterói, RJ, Brazil.

Corresponding address: Dr. Eduardo Moreira da Silva - Universidade Federal Fluminense, Faculdade de Odontologia - Rua Presidente Pedreira, no 97 / 904 CEP 24210-470, Ingá, Niterói, RJ, Brasil Phone: 5521 2629-9832. Fax: 5521 2622-5739. e-mail: emsilva@vm.uff.br

Received: August 16, 2006 - Modification: December 14, 2006 - Accepted: April 04, 2007

\begin{abstract}
$O$

bjective: The purpose of this study was to evaluate the influence of dentin deproteinization on the nanoleakage phenomenon. Material and Methods: Class V cavities were prepared in 12 human molars with cervical margins located in dentin. The cavities were assigned to 2 groups $(n=6)$ according to dentin treatment: Group I - dentin treated in accordance with the manufacturer's instructions and Group II - dentin treated following the manufacturer's instructions $+10 \% \mathrm{NaOCl}$. Each group was sub-divided into three groups, according to the DBS (dentin bonding system) used: Scotchbond Multi Purpose (SBMP), Prime \& Bond NT (PB) and Clearfil SE Bond (SE), which were applied according to manufacturer's instructions. The cavities were restored with composite resin, and the specimens were immersed in a tracer agent $\left(\mathrm{AgNO}_{3} 50 \%\right)$ for $24 \mathrm{~h}$. The teeth were sectioned buccolingually through the center of the restorations, and nanoleakage pattern was evaluated by scanning electron microscopy (SEM) using the backscattered electron image mode. Results: SEM analysis showed different nanoleakage patterns for each DBS. Irrespective of dentin treatments, all SBMP specimens showed nanoleakage. SE did not show any nanoleakage with both dentin treatments used. PB showed nanoleakage within the hybrid layer only in Group I. Conclusions: The influence of dentin deproteinization on the nanoleakage phenomenon was dependent on dentin bonding system formulation and bonding strategies.
\end{abstract}

Uniterms: Dentin-bonding agents; Collagen; Scanning electron microscopy; Nanoleakage.

\section{INTRODUCTION}

Dentin demineralization by acid etching is a complex and superficial procedure, in which not only the smear layer is removed, but also a collagen mesh of approximately 3 to 7.5 ìm is exposed ${ }^{17}$. Underneath this demineralized layer, a partially demineralized zone appears, characterized by increased mineralization and followed by non-etched dentin $^{21}$.

The term nanoleakage was introduced by Sano, et al. ${ }^{26}$, in 1995, to describe a specific type of leakage, which exists even in the absence of marginal gaps. This leakage occurs laterally, through submicron porosities (estimated to be about 20 to $100 \mathrm{~nm}$ in width) at the base of the hybrid layer, which have not been filled with adhesive resin or which have been left poorly polymerized ${ }^{27,37}$. This demineralized, but not fully hybridized dentin layer can be considered a weak point in the adhesion mechanism that could allow dentinal and oral fluid to slowly permeate the interface, and this is believed to degrade the adhesive resin ${ }^{26}$.

Sodium hypochlorite $(\mathrm{NaOCl})$ has been used as a deproteinizing and nonspecific agent ${ }^{18}$ capable of removing organic material exposed after dentin acid etching ${ }^{10,18,24,37}$. Wakabayashi, et al. ${ }^{39}$ (1994) findings indicate that a 60second treatment with $10 \% \mathrm{NaOCl}$ is sufficient for effectively eliminate the exposed collagen layer after acid etching.

Several studies have questioned the real influence of the collagen layer on the adhesion mechanism $9,10,14,18,22,24,28,37,38$. Removal of the collagen mesh may benefit the dentin-adhesive system interaction due to the increase in dentin wettability. This adhesive protocol exposes a subsuperficial dentin layer with nearly the same characteristics as that of the etched enamel, i.e. a larger presence of hydroxyapatite crystals with high surface energy that increases adhesive strength and improves adhesion ${ }^{2,4}$.

Silver nitrate solution $50 \%(\mathrm{w} / \mathrm{v})\left(\mathrm{AgNO}_{3}\right)$ is the most used tracer for evaluation of the nanoleakage phenomenon ${ }^{1,5,8,19,25-27,30}$. This solution can penetrate the dentin due to the small silver ion size $(0.059 \mathrm{~nm} \text { in diameter })^{35}$. Contrasting the size of this ion with the size of some bacteria (0.5-1.0 $\mu \mathrm{m})^{7}$ yields considerable information about the results obtained in evaluating the nanoleakage phenomenon. 
The aim of this study was to evaluate the influence of $10 \% \mathrm{NaOCl}$ on the nanoleakage phenomenon. The research hypothesis was that dentin treatment with $10 \% \mathrm{NaOCl}$ would prevent the occurrence of nanoleakage.

\section{MATERIAL AND METHODS}

Three commercially available adhesive systems, chosen in accordance with their different formulations (organic solvent, hydrophilic monomers and filler particle) and application protocol, were used in this study. Their compositions are described on Table 1.

Twelve extracted non-carious molars stored in a solution of $1 \%$ chloramine for 1 week and frozen in distilled water for less than two months were used in this study. Standardized saucer-shaped cervical cavities $(2.0 \mathrm{~mm}$ high, $2.0 \mathrm{~mm}$ wide and $2.0 \mathrm{~mm}$ deep) with cervical margins located in dentin were cut on buccal and lingual surfaces of the teeth. Cylindrical diamond burs (1092; KG Sorensen, São Paulo, SP, Brazil) in a high-speed handpiece fixed in a special sample aligning device were used for cavity preparation. Hand cutting instruments (hoes - 1258 26, Duflex, São Paulo, SP, Brazil) were used to provide adequate cavity finishing. The teeth were randomly assigned to 2 groups of six teeth each, according to the dentin surface treatment: Group I - Dentin surfaces were etched with $37 \%$ phosphoric acid (3M/ESPE, St. Paul, MN, USA) for $15 \mathrm{~s}$, thoroughly rinsed with airwater spray for $30 \mathrm{~s}$ and blotted dry with tissue paper to standardize moisture; Group II - After the same procedure as applied to Group I, a $10 \% \mathrm{NaOCl}$ gel was left on dentin surface for $1 \mathrm{~min}$, water rinsed for $30 \mathrm{~s}$ and blotted dry with tissue paper

After dentin treatment, the adhesive systems were applied strictly in accordance with the manufacturers' recommendations ( 2 sided prepared teeth, to total 4 cavities per group). For SE, a self etching primer system, the dentin surface was not etched with phosphoric acid in Group I. In Group II, the $\mathrm{NaOCl}$ was applied before the acidic primer. The cavities were restored with two increments of a composite resin (Z 250; 3M/ESPE, St. Paul, MN, USA) light cured for $20 \mathrm{~s}$ with a light-curing unit with light intensity of $500 \mathrm{~mW} / \mathrm{cm} 2$ (QHL 75; Dentsply/Caulk, Milford, DE, USA). After storage in water at $37^{\circ} \mathrm{C}$ for $24 \mathrm{~h}$, the restorations were finished using Super Snap disks (Shofu Inc., Kyoto, Japan). Root apices were sealed with a cyanoacrylate adhesive (Super Bonder $^{\mathrm{TM}}$, 3M, São Paulo, SP, Brazil) and the teeth were coated with two layers of nail varnish up to approximately $0.5 \mathrm{~mm}$ from restoration margins. The specimens were immersed in a $50 \%(\mathrm{w} / \mathrm{v})$ silver nitrate solution for $24 \mathrm{~h}$, rinsed under running water for $5 \mathrm{~min}$, immersed in a photodeveloping solution, and exposed to a fluorescent light for $8 \mathrm{~h}$. After being removed from the photodeveloping solution, the specimens were rinsed under running water for $5 \mathrm{~min}$, and sectioned buccolingually through the center of the restorations by using a low speed diamond saw (7016; KG Sorensen, São Paulo, SP, Brazil). The cut surfaces were embedded in epoxy resin (Resi-line, Rio de Janeiro, RJ, Brazil) and polished with increasingly fine diamond pastes $(6,3,1$ ? $\mu \mathrm{m}$; Buehler Ltd., Lake Bluff, IL, USA). The specimens were ultrasonicated in distilled water for 5 minutes, air dried, mounted on aluminum stubs and sputter-coated with $\mathrm{Au}-\mathrm{Pd}$. The nanoleakage patterns were observed by scanning electron microscopy (JSM-5310, Jeol, Tokyo, Japan) using the backscattered electron image mode.

\section{RESULTS}

Figures 1-3 are representative of dentin specimens subjected to the experimental conditions.

TABLE 1- Bonding Systems used in this study

DBS Composition

Acetone, D and T-methacrylate resins, UDMA, PENTA, functionalized amorphous silica (8\%), cetylamine hydrofluoride, photoinitiators, stabilizer

Clearfil SE Bond
Prime \& Bond NT

(PB)
Primer: Water, Ethanol, 10-MDP, HEMA, hydrophilic dimethacrylate, di-camphoroquinone, N,N-diethanol ptoluidine

Adhesive: 10-MDP, Bis-GMA, HEMA, hydrophobic dimethacrylate, camphoroquinone, $\mathrm{N}, \mathrm{N}$-diethanol p-toluidine, silanated colloidal silica

\section{Manufacturer}

Dentsply Caulk, Milford, DE, USA

Kuraray Medical Inc., Tokyo, Japan

3M ESPE, St Paul, MN, USA 
When the SBMP specimens were only acid-etched, the hybrid layer was approximately 5 - $\mu \mathrm{m}$-thick. Silver was deposited along the hybrid layer and inside some dentin tubules (Figure 1a). This specimen shows structures suggesting water trees, projecting from the hybrid layer up to the adhesive layer. This phenomenon represents residual water channels trapped within the adhesive layer. Figure $1 \mathrm{~b}$ shows the resin-dentin interface of the $\mathrm{NaOCl}$ deproteinized specimen bonded with SBMP. The hybrid layer is not apparent. A thin and discontinuous silver deposit can be observed along the resin-dentin interface. In some parts, patches of silver deposits appeared between some resin tags and tubule walls. Silver deposits can also be seen within the adhesive layer. This finding was observed in most specimens bonded with SBMP. SBMP showed the greatest silver deposition of all tested bonding systems. For PB, in specimens only acid-etched, silver deposit occurred almost throughout the entire thickness of the hybrid layer and along the tubule walls (Figure 2a). In deproteinized specimens, PB did not show silver deposits (Figure 2b). In SE, no silver deposits were seen at the adhesive-dentin interface, irrespective of the dentin treatment (Figure $3 a$ and $3 b$ ).

\section{DISCUSSION}

Despite their different formulations, adhesive systems should be able to provide adequate cavity wall-resin interface sealing. The adhesive systems are composed of a distinct association of hydrophilic and hydrophobic monomers dissolved in an organic solvent, such as water, ethanol or acetone. The adhesion mechanism includes dentin surface demineralization either by phosphoric acid solutions ${ }^{6}$ or by self-etching primers. The nanospaces created on the collagen mesh after etching are filled with resin monomers that copolymerize in situ, creating the so called hybrid layer ${ }^{15}$.

The nanoleakage phenomenon was first described by Sano, et al. ${ }^{25}$ (1994) and was associated with the diffusion of ions or molecules throughout the nanometric spaces located inside the hybrid layer. It was reported that even in the absence of gaps, silver ions could penetrate the hybrid layer and that this finding could be linked to inefficient monomer diffusion through a demineralized collagen layer.

$\mathrm{NaOCl}$ is a well-known nonspecific proteolytic agent ${ }^{39}$ and its collagen removal ability has been evaluated in previous studies ${ }^{3,9,10,18,22,24,38,39}$. Furthermore, recent studies reported that collagen removal with $10 \% \mathrm{NaOCl}$ prevented the nanoleakage phenomenon ${ }^{7,20}$.

In the present study, a $50 \%(\mathrm{w} / \mathrm{v})$ silver nitrate solution was used as a tracer to evaluate the nanoleakage phenomenon. There is a possibility, however, that the low $\mathrm{pH}$ of this solution may over-demineralize dentin and create artificial paths along the dentin-adhesive interface, thus masking the nanoleakage results ${ }^{19}$. Consequently, some previous studies proposed the use of less acidic silver nitrate solutions to evaluate the nanoleakage phenomenon ${ }^{7,31,32}$. A previously published study, however, presented evidences that would support the use of $50 \%(\mathrm{w} /$ v) silver nitrate solution in nanoleakage evaluation ${ }^{12}$. In the aforementioned study, no differences were found between the nanoleakage patterns in specimens placed in silver nitrate solutions with high or low concentrations, and with $\mathrm{pH}$ ranging from 3.4 to 6 . Moreover, Tay, et al. ${ }^{31}$ (2002) showed similar nanoleakage patterns for self-etch adhesives after immersion in both types of silver nitrate [i.e., conventional and less acidic (ammoniacal)]. Based on these studies, it may be assumed the results of the present study as useful for making inferences about the nanoleakage phenomenon.

Since $\mathrm{NaOCl}$ dentin treatment did not prevent the nanoleakage phenomenon with PB and SBMP dentin bonding systems, the research hypothesis was rejected. Irrespective of the dentin treatment, SBMP showed the largest silver deposition within the hybrid layer and the dentin tubules (Figures 1a and 1b). Figure 1a shows a reticular mode of nanoleakage. According to previous studies $^{31,32}$, this nanoleakage pattern represents discontinuous islands of silver deposits within the hybrid layers, and could be related to areas of incomplete water removal from dentin-resin interfaces, instead of incomplete adhesive infiltration. In addition, the authors of the present study hypothesize that the water present as solvent in SBMP primer could have contributed to this pattern of nanoleakage. Structures suggesting water tree formation with approximately $2.5 \mu \mathrm{m}$ projecting from the hybrid layer to the adhesive layer can be seen in Figure 1a. Some previous studies have shown that fluid movement through these channels could degenerate the bonds over time ${ }^{23,29}$. As this finding has been attributed to residual water channels trapped within the adhesive layer ${ }^{31}$, this phenomenon would not be expected to occur with SBMP. Reis, et al. ${ }^{23}$ (2003), analyzing the nanoleakage patterns of water-based single step and two-step self-etching DBS have shown water tree formation within the adhesive layer. The authors claimed that the presence of water, organic solvents, and highly acidic monomers in these simplified DBS leads to poor monomer copolymerization and HEMA hydrogel formation, and might be responsible for the occurrence of this phenomenon $^{30}$. However, SBMP is a three-step DBS, which presents a hydrophilic primer and a hydrophobic resin in separate bottles (Table 1), and in its application protocol, the light-polymerized hydrophobic adhesive is applied over the primer. Theoretically, these features would avoid water tree formation. The only reasonable hypothesis that could be speculated to explain this water trees formation observed with SBMP is that the residual water from the primer, which is not light-activated, could not have been completely evaporated $^{41}$, thus mixing with the hydrophobic resin during adhesive application. It is possible that this water might have formed hydrogen bonds with HEMA from SBMP adhesive $^{32}$, delaying its evaporation, and consequently favoring water tree formation. Further research is necessary to support this possibility. Figure $1 \mathrm{~b}$ shows isolated silver deposits within the adhesive layer and a thin and discontinuous line of silver along the resin-dentin interface. The authors speculate that this might be related to water domains formed around altered $\mathrm{NaOCl}$ collagen not 


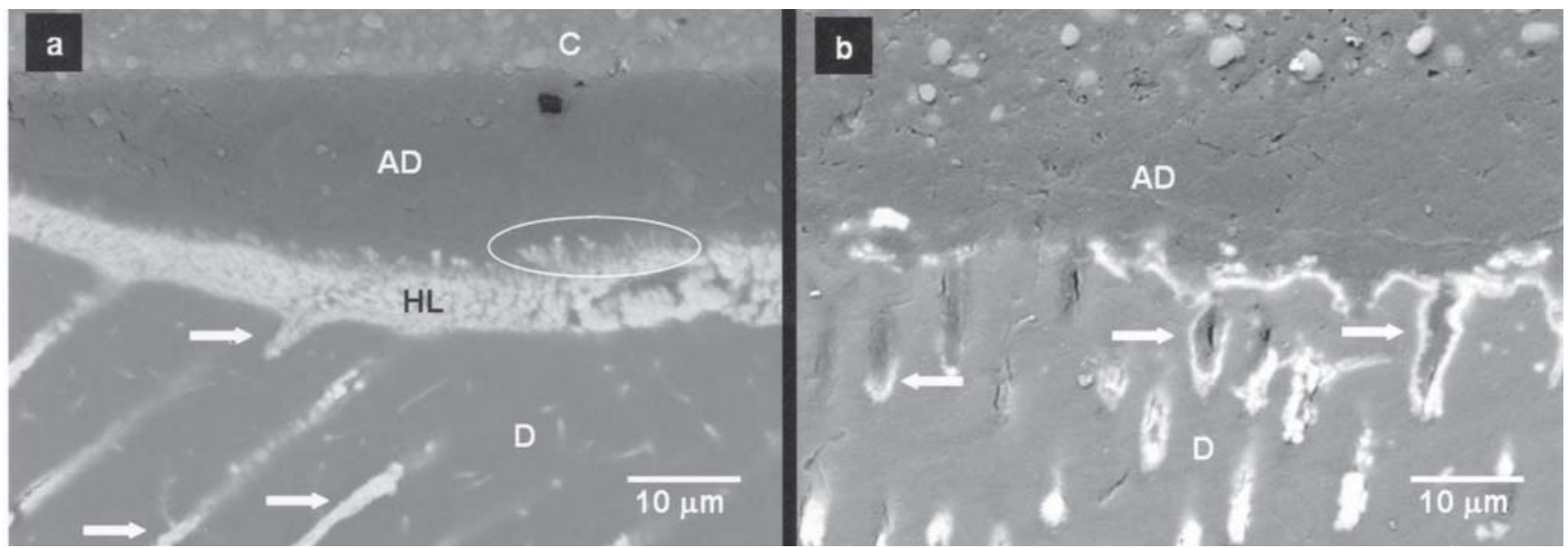

FIGURE 1- Backscattered SEM images of the resin-dentin interface bonded with SBMP (2500x). In (a), acid-etched specimen. Intense silver deposition occurred within the hybrid layer and along the dentin tubules (arrows). Structures suggesting water-tree formation can be seen projecting from hybrid layer to adhesive layer (ellipse). In (b), acid-etched specimen treated with $\mathrm{NaOCl}$. The hybrid layer is not apparent. The nanoleakage pattern showed a thin and discontinuous silver deposition along the resin-dentin interface (ellipsis) and between resin tags and tubule walls (arrows). Amorphous silver structures can be seen within the adhesive layer (pointers). (D) dentin; (C) composite resin; (HL) hybrid layer; (AD) adhesive layer

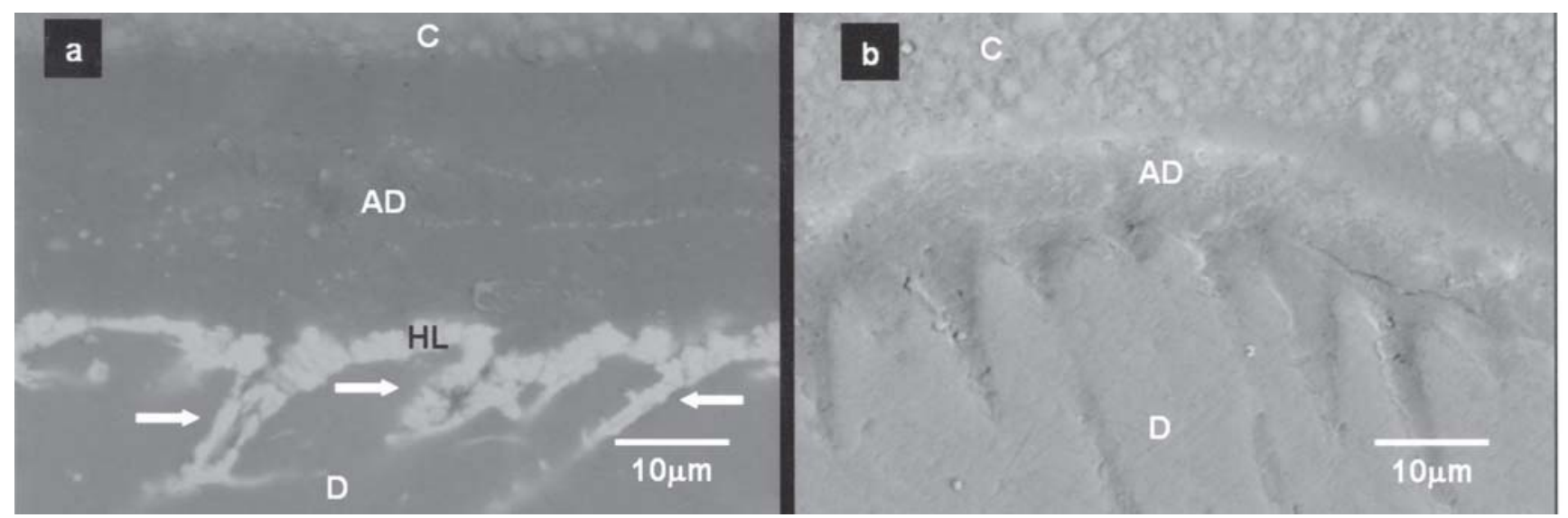

FIGURE 2- Backscattered SEM images of the resin-dentin interface bonded with PB (2500x). In (a), acid-etched specimen. Intense accumulation of silver grains can be observed within the hybrid layer and along the dentin tubules (arrows). In (b), acid-etched specimen treated with $\mathrm{NaOCl}$. No silver deposition could be observed along the interface. (D) dentin; (C) composite resin; (HL) hybrid layer; (AD) adhesive layer
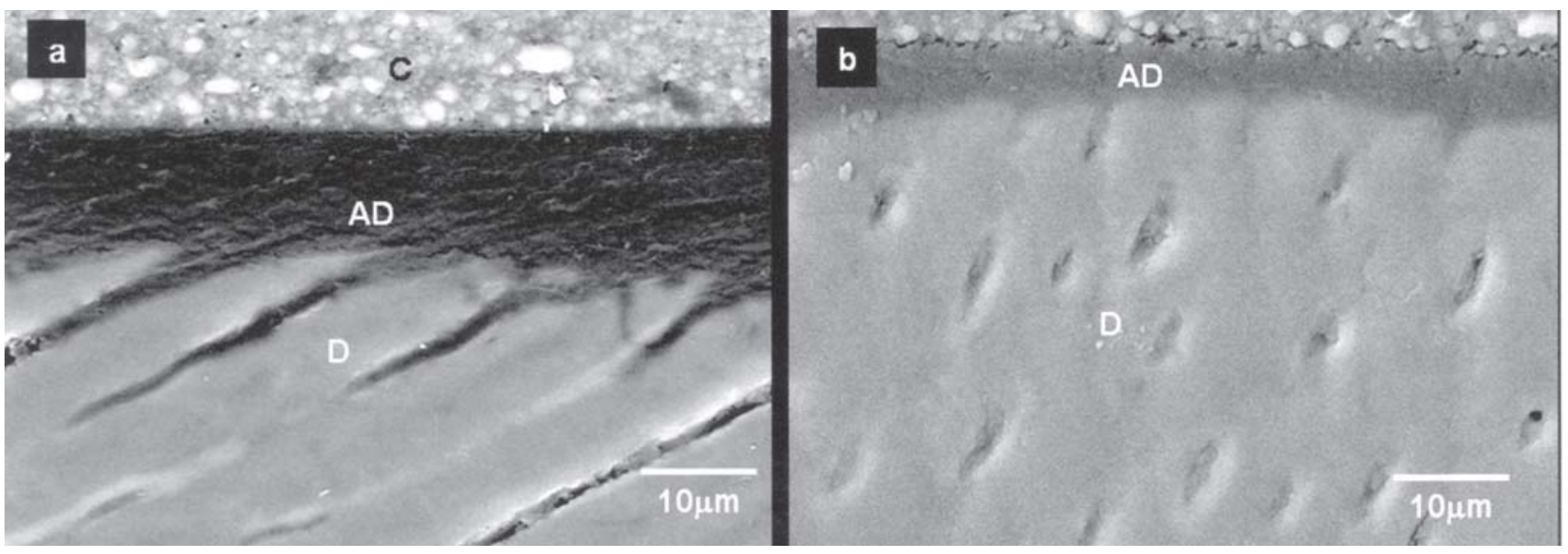

FIGURE 3- Backscattered SEM images of the resin-dentin interface bonded with SE (2500x). In (a), acid-etched specimen and in (b), acid-etched specimen treated with $\mathrm{NaOCl}$. No silver deposition could be observed along the dentin-resin interface in both dentin treatments. (D) dentin; (C) composite resin; (AD) adhesive layer 
completely removed by water-spray washing before SBMP application.

SBMP presents polyalkenoic acid copolymer in its formulation. Some authors report that this copolymer can chemically interact with calcium ions in the dentin ${ }^{28}$. Van Meerbeek, et al. ${ }^{34}$ (1996) also found silver ions within the hybrid layer. In a TEM study, these authors found an amorphous electron-dense phase at the top of the hybrid layer for SBMP, and recorded a high concentration of calcium and oxygen in it. They suggested that it most likely represented a phase separation of the polyalkenoic acid copolymer from the other primer components, as it reacted with calcium to form a calcium-polycarboxylate salt. This amorphous phase was not seen in specimens treated with an experimental primer that did not contain polyalkenoic acid. It can be speculated that oxygen could negatively influence monomer polymerization, allowing minute bubble formation within the hybrid layer and consequently turning it into a porous and degenerating zone. From these findings, it can be speculated that the SBMP bonding mechanism does not imply the establishment of any kind of chemical adhesion to human dentin.

No nanoleakage was observed in deproteinized PB specimens. Indeed, Goes, et al. ${ }^{7}$ (2004) did not find nanoleakage in specimens treated with Prime \& Bond 2.1, a bond system from the same manufacturer, which only differs with respect to the presence of nanometric silica particles in its composition. The presence of acetone as organic solvent could contribute to this PB behavior. The high diffusion of acetone, together with a high water displacement capacity, could result in better PB contact with the deproteinized dentin, thus avoiding the establishment of nanoleakage. In addition, previous studies have shown that the low $\mathrm{pH}$ (1.5 $-2.0)$ of this bonding system may be able to re-etch the mineral phase of the deproteinized dentin, creating a nanohybrid layer ${ }^{22,28}$. From this point of view, the absence of nanoleakage seen on Figure $2 \mathrm{~b}$ can be related to a dentin reconditioning after $\mathrm{NaOCl}$ treatment, increasing the substrate surface energy and enhancing the PB interaction with dentin. These findings lead the authors to presume that dentin deproteinization may benefit low $\mathrm{pH}$ and acetone based bonding systems.

The etched-only PB specimens showed extensive silver deposit in the hybrid zone and inside the dentinal tubules (Figure 2a). This finding is in agreement with Li, et al. ${ }^{11}$ (2000). Two aspects could explain this behavior. Firstly, PB does not contain HEMA in its composition. The -OH groups in these hydrophilic monomers increase the surface free energy of dentin, enhancing the adhesive system wettability ${ }^{2}$. Consequently, it is reasonable to speculate that the absence of HEMA could reduce the ability of PB to diffuse through collagen fibers exposed after etching ${ }^{16}$. Secondly, UDMA and PENTA are high molecular weight monomers that also possibly reduce the $\mathrm{PB}$ ability to diffuse through demineralized dentin ${ }^{28}$. Further studies should be done in order to establish whether PENTA is less efficient than HEMA with regard to the dentin adhesion mechanism ${ }^{11}$.

$\mathrm{SE}$ is a water-based self-etching system, which has an acidic primer that dissolves the smear layer and demineralizes superficial dentin. As this system does not require previous acid-etching, some of the drawbacks, such as dentin overetching, over-moistening and over-drying can be avoided, thus making this bonding system less sensitive to clinical variations. Moreover, according to Toba, et al. ${ }^{33}$ (2003) an important feature related to successful bonding is averting the collapse of the collagen mesh exposed after acid-etching

In the present study, SE primer was applied after dentin treatment with $\mathrm{NaOCl}$ in Group II, and at first sight, this may seem illogical. However, Inai, et al. ${ }^{10}$ (1998), showed a significant increase in the bond strength of a self-etching experimental adhesive when applied after dentin $\mathrm{NaOCl}$ treatment. According to these authors, some kind of interaction between the phosphate groups of the phosphoric acidic ester present in the adhesive formulation and the calcium ions left on dentin surface after $\mathrm{NaOCl}$ treatment could have been responsible for this increase in bond strength. The 10-MDP present in the SE formulation also has phosphate groups in its molecules, and a previous study ${ }^{35}$ showed that this acidic monomer has the ability to chemically adhere to the calcium in dentin. From this point of view, the authors thought reasonable to investigate the effect of $\mathrm{NaOCl}$ dentin treatment before SE primer application on the nanoleakage phenomenon.

Figures $3 \mathrm{a}$ and $3 \mathrm{~b}$ show that irrespective of dentin treatment, no nanoleakage was observed in SE specimens. In $\mathrm{NaOCl}$ treated specimens no hybrid layer could be observed, as shown in Figure 3b. It is reasonable to assume that these findings are associated with the presence of 10methacryloyloxydecyl dihydrogen phosphate (10-MDP) in SE formulation. As a phosphoric acid ester, 10-MDP has a mild decalcification power $(\mathrm{pH}-2.0)$ causing less dentin mineral removal and less collagen exposure. As a self-etching system, the monomers demineralize and penetrate the dentin simultaneously, theoretically allowing complete adhesive diffusion, thus producing a hybrid layer with fewer defects ${ }^{7}$. This behavior reflects the results shown in a previous study ${ }^{8}$, which concluded that simultaneous monomer infiltrations allow adequate adhesion and restoration sealing.

While no differences in nanoleakage were found between the groups, the authors speculated that dentin treatment with $\mathrm{NaOCl}$ before SE primer application in Group II could have removed the organic content of the smear layer, acting as a cleaning agent, thus enhancing the contact between the 10-MDP acidic monomer and the intact superficial dentin. Another aspect that could explain the SE performance is the presence of camphoroquinone as a photoinitiator in its primer. Miyazaki, et al. ${ }^{13}$ (1995), showed an increase in bond strength for DBS that have camphoroquinone as a photoinitiator in their primers and claimed that this increase in bond strength would suggest an improvement in the polymerization of the DBS impregnated into the dentin substrate. Since SBMP and PB also have camphoroquinone as a photoinitiator, the same behavior claimed here for SE could be expected. Two aspects, however, must be taken into account: firstly, in SBMP, the camphoroquinone is present only in the hydrophobic resin; secondly, $\mathrm{PB}$ is a 
DBS in which organic solvent, hydrophilic and hydrophobic monomers are mixed in a single bottle. Thus, it is possible that the absence of HEMA and the presence of high molecular weight monomers, i.e. UDMA and PENTA, as aforementioned, could have masked this effect of camphoroquinone in $\mathrm{PB}$.

\section{CONCLUSIONS}

The influence of $\mathrm{NaOCl}$ dentin treatment on the nanoleakage phenomenon was dependent on bond system formulation and on its interaction with the substrate. The tested acetone-based system was the only DBS that showed beneficial results when used in association with the deproteinizing pre-treatment agent.

\section{REFERENCES}

1- Agee KL, Pashley EL, Ittahagarun A, Sano H, Tay FR, Pashley DH. Submicron hiati in acid-etched dentin are artifacts of desiccation. Dent Mater. 2003;19:60-8

2- Attal JP, Asmussen E, Degrange M. Effects of surface treatment on the free surface energy of dentin. Dent Mater. 1994;10:259-64.

3- Breschi L, Gobbi P, Chersoni S, Mazzotti G, Prati C. Effects of different acid and sodium hypochlorite treatments on dentin collagen: a FEISEM analysis. Am J Dent. 2003;16(sp. issue):77A-81A.

4- Carvalho RM, Chersoni S, Frankenberger R, Pashley DH, Prati C, Tay FR. A challenge to the conventional wisdom that simultaneous etching and resin infiltration always occurs in self etch adhesives. Biomaterials. 2005;26:1035-42.

5- Frankenberger R, Pashley DH, Reich SM, Lohbauer U, Petschelt A, Tay FR. Characterization of resin-dentine interfaces by compressive cyclic loading. Biomaterials. 2005;26:2043-52.

6- Fusayama T, Nakamura M, Kurosaki N, Iwaku M. Non-pressure adhesion of a new adhesive restorative resin. J Dent Res. $1979 ; 58: 1364-70$

7- Goes MF, Montes MAJR. Evaluation of silver methenamine method for nanoleakage. J Dent. 2004;32:391-8.

8- Guzmán-Armstrong S, Armstrong SR, Qian F. Relationship between nanoleakage and microtensile bond strength at the resin-dentin interface. Oper Dent. 2003;28:60-6.

9- Gwinnet AJ, Tay FR, Pang KM, Wei HY. Quantitative contribution of the collagen network in dentin hybridization. Am J Dent. 1996;9:140-4

10 - Inai N, Kanemura N, Tagami J, Watanabe LG, Marshall SJ, Marshall GW. Adhesion between collagen depletes dentin and dentin adhesives. Am J Dent. 1998;11:123-7.

11 - Li H, Burrow MF, Tyas MJ. Nanoleakage patterns of four dentin bonding systems. Dent Mater. 2000;16:48-56.

12- Li H, Burrow MF, Tyas MJ. The effect of concentration and $\mathrm{pH}$ of silver nitrate solution on nanoleakage. J Adhes Dent. 2003;5:1925 .
13 - Miyazaki M, Hinoura K, Saito H, Onose H, Moure BK. Influence of light irradiation of dentin primers on dentin-resin bond. J Dent. $1995 ; 23: 371-4$.

14- Muench A, Silva EM, Ballester RY. Influence of different dentinal substrates on the tensile bond strength of three adhesive systems. J Adhes Dent. 2000;2:209-2.

15- Nakabayashi N, Kojima K, Masuhara E. The promotion of adhesion by the infiltration of monomers into tooth substrates. J Biomed Mater Res. 1982;6:265-73

16- Nakabayashi N, Takarada K. Effect of HEMA on bonding to dentin. Dent Mater. 1992;8:125-30.

17- Perdigão J, Lambrechts P, Van Meerbeek B, Vanherle G, Lopes AL. Field emission SEM comparison of four postfixation drying techniques for human dentin. J Biomed Mater Res. 1995;29:1111-20

18- Perdigão J, Thompson JY, Toledano M, Osorio R. An ultra morphological characterization of collagen depleted etched dentin. Am J Dent. 1999;12:250-5.

19- Pereira PNR, Okuda M, Nakajima M, Sano H, Tagami J, Pashley DH. Relationship between bond strengths and nanoleakage: evaluation of a new assessment method. Am J Dent. 2001;14:100-4.

20 - Pioch T, Kobaslija S, Huseinbegovic A, Müller K, Dörfer CE. The effect of $\mathrm{NaOCl}$ dentin treatment on nanoleakage formation. J Biomed Mater Res. 2001;56:578-83.

21 - Pioch T, Staehle HJ, Duschner H, García-Godoy F. Nanoleakage at the composite dentin interface: a review. Am J Dent. 2001;14:252-

22- Prati C, Chersoni S, Pashley DH. Effect of removal of surface collagen fibrils on resin - dentin bonding. Dent Mater. 1999;15:32331 .

23 - Reis AF, Arrais CAG, Novaes PD, Giannini M. Ultramorphological analysis of the resin-dentin interface: nanoleakage patterns of simplified dental adhesives. Acta Microsc. 2003;12:575-6.

24- Saboia VPA, Rodrigues AL, Pimenta LAF. Effect of collagen removal on shear bond strength of two single bottle adhesives systems. Oper Dent. 2000;25:395-400.

25- Sano H, Shono T, Takatsu T, Hosoda H. Microporous dentin zone beneath resin-impregnated layer. Oper Dent. 1994;19:59-64.

26- Sano H, Takatsu T, Ciucchi B, Horner JA, Mattews WG, Pashley DH. Nanoleakage: leakage within the hybrid layer. Oper Dent. 1995;20:18-35.

27- Sano H, Yoshiama M, Ebisu S, Burrow, MF, Takatsu T, Ciucchi B, et al. Comparative TEM and SEM observations of nanoleakage within the hybrid layer. Oper Dent. 1995;20:160-7.

28- Silva EM. Influência do conteúdo orgânico da dentina no mecanismo de adesão de sistemas adesivos hidrófilos [tese]. São Paulo (SP): Faculdade de Odontologia, Universidade de São Paulo; 2002.

29- Smith DC. Polyacrylic acid-based cements: adhesion to enamel and dentin. Oper Dent. 1992;5:177-83.

30- Tay FR, King NM, Chan K, Pashley DH. How can nanoleakage occur in self-etching adhesive systems that demineralize and infiltrate simultaneously? J Adhes Dent. 2002;4:255-69.

31 - Tay FR, Pashley DH. Yoshiyama M. Two modes of nanoleakage expression in single-step adhesives. J Dent Res. 2002;81:472-6. 
32- Tay FR, Pashley DH, Yiu C, Cheong C, Hashimoto M, Itou K, et al. Nanoleakage types and potential implications: evidence form unfilled and filled adhesives with the same resin composition. Am J Dent. 2004;17:182-90

33 - Toba S, Veerapravati W, Shimada Y, Nikaido T, Tagami J. Microshear bond strengths of adhesive resins to coronal dentin versus the floor of the pulp chamber. Am J Dent. 2003;16:51A-6A.

34- Van Meerbeek B, Conn LJ, Duke ES, Eick JD, Robinson SJ, Guerrero D. Correlative transmission electron microscopy examination of nondemineralized and demineralized resin-dentin interfaces formed by two dentin adhesive systems. J Dent Res. $1996 ; 75: 879-88$

35- Van Meerbeek B, De Munck J, Yoshida Y, Inoue, Vargas M, Van Landyut $\mathrm{K}$, et al. Adhesion to enamel and dentin: current status and future challenges. Oper Dent. 2003;28:215-35.

36- Van Meerbeek B, Vargas M, Inoue S, Yoshida Y, Perdigão J, Lambrechts P, et al. Microscopy investigations: techniques, results, limitations. Am J Dent. 2000;13:3D-18D.

37 - Varela SG, Rábade SB, Lombardero PR, Sixto JML, Bahillo JDG, Park SA. In vitro study of endodontic post cementation protocols that use resin cements. J Prosthet Dent. 2003;89:146-53.

38 - Vargas MA, Cobb DS, Armstrong SR. Resin dentin shear bons strength and interfacial ultra structure with and without a hybrid layer. Oper Dent. 1997;22:159-66.

39- Wakabayashi Y, Kondou Y, Suzuki K, Yatani H, Yamashita A Effect of dissolution of collagen on adhesion to dentin. Int $\mathrm{J}$ Prosthodont. 1994;7:302-6.

40 - Yamauti M, Hashimoto M, Sano H, Ohno H, Carvalho RM, Kaga $\mathrm{M}$, et al. Degradation of resin-dentin bonds using $\mathrm{NaOCl}$ storage. Dent Mater. 2003;19:399-405.

41 - Yiu CKY, Pashley EL, Hirashi N, King NM, Goracci G, Ferrari M, et al. Solvent and water retention in dental adhesive blends after evaporation. Biomaterials. 2005;26:6863-72. 